organisms. Analytical sensitivity was determined using titered, purified CT elementary bodies and cultured NG cells.

Results The Xpert CT/NG assay detects all CT serovars, new variant CT, and 48 geographically diverse NG strains.

The CT primers and probes do not cross-react with DNA or RNA from non-trachomal species. All non-gonococcal Neisseria species yielded negative results, including $\mathrm{N}$. mucosa and $\mathrm{N}$. cinerea, because both NG targets must be PCR positive for a "NG DETECTED" result.

The LoDs for the Xpert CT/NG Assay for CT serovar D in male urine and vaginal swab matrix respectively were 75 and $84 \mathrm{~Eb} / \mathrm{mL}$; for CT serovar H, LoDs were 134 and $161 \mathrm{~Eb} / \mathrm{mL}$. In both matrices, the LoD for two NG strains was approximately $2 \mathrm{cfu} / \mathrm{mL}$.

Conclusion The Xpert CT/NG assay is highly specific and sensitive. The ease of use and fast time to result could lead to reduced time to treatment of CT and NG infections.

\section{P2.015 EVALUATION OF THE TRIPLEX REAL-TIME PCR ASSAY FOR DETECTION OF CHLAMYDIA TRACHOMATIS AND NEISSERIA GONORRHOEAE IN URINE AND VAGINAL SWABS}

doi:10.1136/sextrans-2013-051184.0280

'T Samleerat, 'S Pookkapund, 'S Techanun, ${ }^{2} \mathrm{~K}$ Jitvatcharanon, 'P Leechanachai. 'Faculty of Associated Medical Sciences, Chiang Mai University, Chiang Mai, Thailand; ${ }^{2}$ STD and AIDS Control Center Region 10, Department of Communicable Disease Control, Ministry of Public Health, Chiang Mai, Thailand

Background Chlamydia trachomatis and Neisseria gonorrhoeae are among the most common causes of sexually transmitted bacterial infections worldwide. Infection with these organisms is mostly asymptomatic, however serious complications are also observed. Screening of the diseases is necessary to identify, treat and control the infection. In this study, we evaluated the performance of the triplex real-time PCR assay with internal control for detection of $\mathrm{C}$. trachomatis and N. gonorrhoeae infections in urine and vaginal swabs.

Methods The performance of TaqMan probe-based triplex real time PCR targeting the cryptic plasmids of C. trachomatis (pCHL1) and $\mathrm{N}$. gonorrhoeae (pJD1) and beta-globin gene as an internal control was assessed using 188 urine specimens and 118 vaginal swabs. The triplex real time PCR was compared with the Roche COBAS AMPLICOR CT/NG assay. The urine specimens were further tested using real-time PCR targeting the $\mathrm{N}$. gonorrhoeae porA pseudogene. Results For urine specimens, the sensitivity and specificity of the triplex real time PCR were $100 \%$ and $97.6 \%$, respectively, for C. trachomatis, and $100 \%$ and $95.2 \%$, respectively, for $\mathrm{N}$. gonorrhoeae. For vaginal swabs, the sensitivity and specificity were $100 \%$ and $100 \%$, respectively, for C. trachomatis, and $100 \%$ and $98.1 \%$, respectively, for N. gonorrhoeae. There were 5 (2.84\%) from 176 urine specimens that were negative for cryptic plasmid, but positive for $\mathrm{N}$. gonorrhoeae porA pseudogene.

Conclusion The performance of the triplex real time PCR assay was comparable to that of the Roche COBAS AMPLICOR CT/NG assay. This assay is easy to perform and the results can be achieved in 3-4 hours, including sample preparation. The estimated cost of triplex real time PCR was less than 20 USD. Taken together with using noninvasive urine sampling, this assay is convenient and suitable for epidemiological studies in screening large number of samples.

\section{P2.016 COMPARISON OF THREE REAL-TIME PCR TESTS FOR THE DETECTION OF CHLAMYDIA TRACHOMATIS AND NEISSERIA GONORRHOEAE IN YOUNG PREGNANT WOMEN}

doi:10.1136/sextrans-2013-051184.0281

${ }^{1,2,3} \mathrm{O}$ Peuchant, ${ }^{1} \mathrm{~S}$ de Diego, ${ }^{1,2} \mathrm{C}$ Le Roy, ${ }^{3} \mathrm{~S}$ Frantz-Blancpain, ${ }^{1,3} \mathrm{C}$ Hocké, ${ }^{1,2,3} \mathrm{C}$ Bébéar, ${ }^{1,2,3} \mathbf{B}$ de Barbeyrac. 'University of Bordeaux, Bordeaux, France; Institut National de la Recherche Agronomique, Bordeaux, France; ${ }^{3}$ Centre hospitalier universitaire, Bordeaux, France
At the Bordeaux University Hospital, among pregnant women aged less than 25 years-old the prevalence of $\mathrm{C}$. trachomatis (CT) and $\mathrm{N}$. gonorrhoeae (NG) is $12.5 \%$ and $2.4 \%$, respectively for those requesting abortion by using the Abbott $\mathrm{m} 2000 \mathrm{CT} / \mathrm{NG}$ test, and $7.9 \%$ and $0 \%$, respectively, for those consulting for monitoring pregnancy by using the Roche Cobas 4800 CT/NG test.

The objective of this study was to evaluate and compare the performances of both of these tests along with a third one, the Cepheid GeneXpert CT/NG, for the detection of CT and NG in vaginal swabs collected from pregnant women consulting for abortion or for monitoring pregnancy. A patient was considered infected if at least two tests were positive.

Among 304 pregnant women included, from September 2012 to January 2013, 34 were infected, leading a prevalence of $11.7 \%$ $(26 / 222)$ for patients requesting abortion and $9.7 \%$ (8/82) for patients consulting for monitoring pregnancy. There were two false CT-positive results with the Abbott m2000, one false negative result reported by Roche and the Cepheid GeneXpert. The sensitivity and specificity were $97 \%$ and $100 \%$ for the Roche and the Cepheid GeneXpert tests, and 100\% and 99.3\% for the Abbott assay. The positive predictive value ranged from $94.4 \%$ to $100 \%$ according to the test.

For NG, 297 specimens were negative and 7 were positive using the three tests. All results were concordant, leading to a sensitivity and specificity of $100 \%$ for all the assays. The prevalence of NG among pregnant women requesting abortion was $2.7 \%(6 / 222)$ and $1.2 \%(1 / 82)$ for those consulting for monitoring pregnancy.

In the populations studied, all three assays have similar performances for CT/NG detection.

\section{P2.017 CLINICAL EVALUATION OF THE PELVOCHECK ${ }^{\circledR}$ CT/NG FOR THE DETECTION OF CHLAMYDIA TRACHOMATIS AND NEISSERIA GONORRHOEAE}

doi:10.1136/sextrans-2013-051184.0282

${ }^{1}$ A Kilic, ${ }^{2} \mathrm{R}$ Kofler, ${ }^{1} \mathrm{~K}$ Hänel, ${ }^{3} \mathrm{~T}$ Meyer. ${ }^{1}$ Greiner Bio-One GmbH, Frickenhausen, Germany; '2ambda GmbH, Rainbach, Austria; ${ }^{3}$ Institut für Medizinische Mikrobiologie, Virologie und Hygiene, Universitätsklinikum Hamburg-Eppendorf (UKE), Germany

Background In the present study the performance of the PelvoCheck $^{\circledR} \mathrm{CT} / \mathrm{NG}$, a microarray-based nucleic acid amplification assay for the detection of Chlamydia trachomatis (CT) and Neisseria gonorrhoeae (NG), was evaluated in single and pooled urine specimen of young women.

Methods A total of 1649 female urine specimens were collected and examined for urogenital chlamydia infections. Because of a low prevalence $(2.12 \%), 50$ CT-negative urine specimens were enriched with CT reference material mimicking the natural chlamydial distribution in female urine. The results were compared to those of the Roche $\mathrm{COBAS}^{\circledR}$ TaqMan $^{\circledR}$ CT assay as the first and the Abbott RealTime CT/NG assay as the second reference method.

Similarly, NG pre-screened female urine specimens (60 NG-positive and 60 NG-negative specimens) were analysed with the PelvoCheck ${ }^{\circledR} \mathrm{CT} / \mathrm{NG}$ test and compared to a validated in-house Q-PCR method and the Abbott RealTime CT/NG assay.

Furthermore, the PelvoCheck ${ }^{\circledR} \mathrm{CT} / \mathrm{NG}$ assay was tested for pooled urine specimens (52 CT-negative and 55 CT-positive specimens). Each pool consisted of either five individual CT-negative specimens or four CT-negative and one CT-positive individual specimens.

Results For the detection of CT the overall positive agreement (sensitivity) and overall negative agreement (specificity) of the PelvoCheck ${ }^{\circledR}$ CT/NG were $98.8 \%$ and $100 \%$, for the detection of NG $98.3 \%$ and $98.2 \%$, respectively.

The comparison of data obtained with the PelvoCheck ${ }^{\circledR}$ CT/NG for pooled urine specimens resulted in a positive agreement of $90.9 \%$ and a negative agreement of $100 \%$. Four CT-positive pooled specimens with final CT-concentrations of $0.05-0.13 \mathrm{IFU} / \mathrm{ml}$ were not detected. 